\title{
Author Correction: Niche harmony search algorithm for detecting complex disease associated high- order SNP combinations
}

Shouheng Tuo ${ }^{1,2}$, Junying Zhang ${ }^{1}$, Xiguo Yuan ${ }^{1}$, Zongzhen $\mathrm{He}^{1}$, Yajun Liu ${ }^{1}$ \& Zhaowen Liu ${ }^{1}$

Correction to: Scientific Reports https://doi.org/10.1038/s41598-017-11064-9, published online 14 September 2017

The Acknowledgements section in this Article is incomplete.

“This work was supported by the Natural Science Foundation of China under Grants 61571341, 61201312, 91530113 and 11401357, Research Fund for the Doctoral Program of Higher Education of China (No. 2013 0203110017), the Fundamental Research Funds for the Central Universities of China (Nos BDY171416 and JB140306), the Natural Science Foundation of Shaanxi Province in China (2015JM6275), Free exploration projects for 2017 basic research-related expenses."

should read:

"This work was supported by the Natural Science Foundation of China under Grants 61571341 and 11401357, the Fundamental Research Funds of China for the Central Universities (Nos JBZ170301 and 20101164977)."

(c) (i) Open Access This article is licensed under a Creative Commons Attribution 4.0 International (c) License, which permits use, sharing, adaptation, distribution and reproduction in any medium or format, as long as you give appropriate credit to the original author(s) and the source, provide a link to the Creative Commons license, and indicate if changes were made. The images or other third party material in this article are included in the article's Creative Commons license, unless indicated otherwise in a credit line to the material. If material is not included in the article's Creative Commons license and your intended use is not permitted by statutory regulation or exceeds the permitted use, you will need to obtain permission directly from the copyright holder. To view a copy of this license, visit http://creativecommons.org/licenses/by/4.0/.

(c) The Author(s) 2018 